\title{
Erratum to: My experimental meanderings
}

\section{John Hey}

Erratum to: Theory Dec. (2014) 77:291-295 DOI 10.1007/s11238-014-9464-X

I must apologise to Noemi Pace for omitting her from my list of co-authors printed at the end of this paper. This final paragraph should read:

"I am fortunate to have many co-authors, most of whom have inspired and encouraged me. Those who have worked with me on experiments include (and I hope that I have not omitted any) Louise Allsopp, David Ansic, Marie-Edith Bissey, John Bone, Roberto Burlando, David Butler, Enrica Carbone, Anna Conte, Valentino Dardanoni, Daniela Di Cagno, Xueqi Dong, Mariateresa Fiocca, Konstantinos Georgalos, Ricardo Goncalves, Jinkwon Lee, Gianna Lotito, Julia Knoll, Anna Maffioletti, Konstantina Mari, Peter Moffat, Andrea Morone, Tibor Neugebauer, Chris Orme, Stefania Ottone, Noemi Pace, Luca Pannacione, Carmen Pasca, Massimo Paradiso, Cristina Pitassi, Martin Reynolds, Karim Sadrieh, Patrizia Sbriglia, Ulli Schmidt, Elisabetta Strazzera, John Suckling and Wenting Zhou. My thanks to all of them. And, once again, my thanks to the organisers of this special issue."

The online version of the original article can be found under doi:10.1007/s11238-014-9464-X.

J. Hey $(\varangle)$

University of York, York, UK

e-mail: john.hey@york.ac.uk 